\title{
Factors Influencing the Acceptance of Mobile Learning in K-12 Education in Saudi Arabia: Towards a Shift in the Saudi Education System vis-à-vis Saudi 2030 Vision
}

\author{
https://doi.org/10.3991/ijim.v16i01.25671 \\ Fahad Alturise $^{1}$, Sami Alshmrany ${ }^{2}$, Tamim Alkhalifah ${ }^{1(\bowtie)}$, Salem Alkhalaf $^{1}$ \\ ${ }^{1}$ Computer Department, Qassim University, Buraydah, Saudi Arabia \\ ${ }^{2}$ Islamic University of Madinah, Madinah, Saudi Arabia \\ tkhliefhaqu. edu.sa
}

\begin{abstract}
The Saudi Arabian government is committed to updating and improving its education system. Thus, in March 2017, a project was declared to convert the existing book-based methodology to modern, mobile technology in the K-12 education space by 2021 . As part of this process, a deep-dive literature review of student acceptance of mobile learning confirmed that there was limited research into what elements influenced how much students were likely to accept learning with mobile applications in the five to 18-year-old demographic of K-12. For this purpose, research hypotheses are developed and questionnaire-based online surveys are designed for data collection, which were shared with 295 students via email in the concerned schools at different education levels, out of which 282 students completed the survey. The survey response is analyzed with a measurement model and structural model. A measurement model is performed via the AMOS tool to measure the average variance extracted, maximum shared variance, and average shared variance. Based on the measurement model, the structure model is built to investigate all the concerning factors. The conclusion of the literature review was that the Saudi Arabian Education Ministry must acquire an understanding of these elements to strategize the implementation of the new technology. This study approached high school students, aged 16 to 18 , in Saudi Arabia, to examine the elements which would influence their acceptance of mobile learning technology. The study combined well-known educational elements, such as learning self-management, system quality, and hedonic motivation, with the Unified Theory of Acceptance and Use of Technology (UTAUT), to create a significant theoretical model for new technology in a high school setting. Conclusions were drawn that societal influence did not affect the student's approach to mobile learning, but that learning self-management, the expectancy of effort and performance, hedonic motivation and the quality of the system did affect the acceptance behavior of the students. It was also noted that gender was not a significant factor in the study.
\end{abstract}

Keywords - mobile learning, secondary education, distance education and online learning 


\section{Introduction}

Mobile devices, such as smartphones, are not simply communication devices; they have become a catalyst for the new social 'tribes' that are coming into being [1]. These devices not only allow us to speak with others over distances, but they also put the world's knowledge at our fingertips through the internet, store our data, and allow us to manage our lives and work. Indeed, in many cases, they let us complete our work, with applications that allow us to word process, send emails, transfer files, produce web sites, and input data into spreadsheets [2]. The potential for communication and information access harnessed by mobile technologies can drastically alter our perceptions of place and reduce our dependence on static, physical places in which to work [3]. Training can be delivered in new and exciting ways, although capability challenges become apparent when people expect their phone to be entirely bespoke to their needs [4]. It has also been said that students expect to be trained at a time and pace that suits them, and not necessarily following a traditional classroom approach.

The wholesale ownership of mobile and wireless devices is altering the environment for learning supported by technology [5]. Also, new technological developments are widely accepted to be altering not only the learning landscape, but also radically changing cultural and societal customs in schools. As most students now possess a mobile device, educators have accepted that M-learning is no longer a fresh concept and that there are numerous benefits to the technology being used [6].

Devices are more powerful than ever and are not purely for phone calls and text messages in the modern world. They are portable computers connected to the internet at ever increasing speeds; they are also recording devices for sound, pictures, and videos. The modern student has become a multi-tasking, collaborative individual, embracing technology in many forms and using M-learning to its full potential [7].

As a new style of computer support and off-site education, M-learning has become part of a new way of thinking, and portable technology and integrated networks support this at all levels of education, from primary school to higher education, due to the current COVID19 pandemic, which greatly affected daily life around the globe. Therefore, alternate M-learning facilitates collaborative working and makes education accessible. As a step forward from E-learning, M-learning pushes accessibility boundaries and makes studying available whenever and wherever [8,9].

Recently, the government of Saudi Arabia announced 'Saudi Vision 2030' to transition the country's economy to a less volatile, investment-based model from an over-reliance on oil revenues. The government believes that the vision's success will depend heavily on education system reforms, creating a more robust basis for the employment of young Saudis. Based on this vision, the Saudi Arabian government announced its intention to digitally transform K-12 education in Saudi Arabia, by removing books and replacing them with mobile technologies [92].

Despite Saudi Arabia, humanity reached its limits in 2020 against natural disasters in the form of the COVID-19 pandemic, where European western countries also tried for e-learning. Among them, Greece was one of the countries that handled this crisis relatively well and was highlighted by the international media [10], whereas Malaysia shifted to an online mode for undergraduates' perception to improve their speaking skills [11]. The user's behavioral intention regarding online distance learning 
is analyzed in [12]. This natural disaster of COVID19 resulted in suspension of and operation of schools and shifting teaching to continue in online teaching mode. Since the transition to online e-learning methods confronted both students and teachers with unknown and unfamiliar methods, this has caused dissatisfaction among both students and teachers [13]. This online mode greatly influences management, leadership, family work conflict, and life satisfaction among school administrators [14-15]. In this regard, authors in [16] analyzed autonomous learning for COVID19 periods. A bibliometric analysis is performed in [17], whereas an alternate mediator assessment role for online learning environments is discussed in [18].

Many studies report it as a serious problem around the globe as well as in different parts of Europe [19-26]. Academic reforms are defined by them as the inability of today's academic institutions to fulfill the demands of modern societies in the west. An artificial divide between classroom and real-life learning has long been an issue, obstructing the transmission of knowledge and skills and creating unwelcome hurdles to re-establishing learning as a guiding framework of inventive problem-solving. Therefore, in this context, researchers in [27] used a statistical pre and posttest wound management competence survey of 192 students to assess pupil reported training improvements in terms of learning, skills, and mindsets. The promotion and innovation to reform the "21st Century Skills Framework" to understand how learning should work in today's social context, as well as the use of robotics, are still ongoing [28].

Despite Europe, this development makes it critically important to investigate the perceptions and acceptance of M-learning at K-12 institutions in Saudi Arabia, which is the main theme of the paper. Remembering that technologies impact on people's learning methods and deliver an effective teaching and learning environment [29], their adoption needs to be well-documented and applied realistically while respecting any distinct local, cultural, and societal environments which support them, and all the relevant constraints and issues which may exist therein [30]. Our study seeks to verify the technique of extending the Unified Theory of Acceptance and Use of Technology (UTAUT) by identifying the critical factors that would ensure the proper implementation of M-learning in institutions across the nation.

Available literature shows few M-learning acceptance studies that have been conducted within a K-12 context where these studies investigated teachers' acceptance of M-learning. Several keywords were used to search for acceptance studies conducted within the K-12 context in different databases such as EdITLib, Academic Search Complete, INSPEC, and Google Scholar. As can be seen from the literature, the number of studies conducted within the university context is greater than the K-12 context. However, no study could be found that had investigated the parameters influencing the acceptance of M-learning by students in the K-12 Saudi Arabian context. Therefore, this paper scope focuses on the influence of these major influencing parameters in mobile learning K-12.

In the following manuscript, section 2 discusses the literature review, section 3 expands on the research hypothesis and model, section 4 analyzes questionnaire development and data collection, section 5 investigates the measurement model, section 6 discusses the structural model, discussion of the results is performed in section 7 , and finally some conclusion is drawn in section 8 with implications for K-12 education. 


\section{$2 \quad$ Literature review}

Over the past decade, diverse studies have investigated peoples' perceptions of implementing M-learning and have documented the M-learning experience in the K-12 context. [35] carried out an experimental study to explore broader learning achievements; the quality of pupil resources, learning attitudes, interactive trends, and skills retention associated with the use of a mobile device (tablet PC). The outcomes indicated that pupil attitudes towards IT-based cooperative mapping are largely positive. The participants in the study claimed that using a mobile device for learning enhanced their passion for the subject (social sciences) as a whole, and that it had the potential to affect their approach to other courses in the same way. Furthermore, most were confident about the use of ITCs as being a good way to improve group cohesion and performance.

From a Saudi Arabian perspective, several investigations have centered on the opinions and attitudes towards M-learning in classrooms among K-12 pupils and teachers. For instance, [32] explored attitudes towards the adoption of ICT resources both inside and outside the learning environment in Riyadh schools. Six schools were involved in the study. The results indicated that there was a high proportion of mobile phone owners among high school students. Furthermore, students have reported positive attitudes towards using ICT technologies in education. Students have expressed very positive feelings towards the current adoption of ICT technologies, but most were keen to see a greater assimilation and more technology in education. Similarly, [33] distributed an online questionnaire with the aim of exploring attitudes and opinions about the current limitations to the acceptance of M-learning in schools among K-12 teachers. Six responses were collected (out of forty high school teachers). The teachers discussed several key problems associated with bringing mobile technology into the classroom, including access to learning resources, the misuse of devices, the lack of a robust infrastructure, and a general lack of experience among staff.

Research regarding technology onboarding has received significant attention from scholars around the world. Researchers have proposed different concepts and assumptions around the acceptance of technology to predict user adoption of the same. These models have been widely implemented and extended. Research which involved testing the constructs of previous models by addressing earlier research, and experimentally comparing the assumptions and their accompanying parameters to develop and validate the UTAUT. According to the same study, the UTAUT returned a better performance than previous models.

To address the K-12 arena, [34] applied the TAM model by handing out a survey to 378 K-12 teachers. Out of the 378 distributed, 99 came back. The results demonstrated that the perception of ease of use, which included technology self-efficacy and usability, was crucial to understanding the recognition and usage of technology by educators. The outcome was the identification of additional teacher training on M-learning to increase their confidence. [35] constructed a theoretical model for predetermining and justifying ICT applications, inclusive of M-learning, among female primary school science teachers. The study gathered data from 500 teachers in Kuwait. It focused on a variety of cognitive variables such as usefulness, external barriers, computer self-efficacy, 
subjective norms, attitude towards using ICT, and how easy it is to use. The results suggested that the only component which didn't have much of an effect was external barriers. Usefulness, computer self-efficacy, subjective norms, and ease of use all had a positive effect on perceptions of the value of IT for learning outcomes.

The work of [36], by adopting TAM method elements, applied a combined method design to teachers to examine their attitudes, confidence, and understanding of M-learning. The study's effectiveness was potentially reduced with only ten participants, but the results implied that teachers are positive and hopeful about implementing M-learning into their teaching methodologies. Factors such as their perception of capability around technology, their positive approach to technical skills, and their attitude towards how easy and effective mobile technologies are to use were viewed as compelling pointers towards M-learning being accepted [37]. By conducting a mixed method study, [38] applied the original UTAUT model to calculate the relevant components of learners' and teachers' positive adoption of M-learning at Namibian secondary schools. Their findings showed that effort and performance expectancy, together with societal influence, are meaningful predictors of M-learning acceptance. [39] proposed that the UTAUT model be used to work out parameters affecting pupils' acknowledgement of M-learning in Egyptian high schools. The researchers added enjoyment, interactivity, and mobility to the initial UTAUT model. It should be noted that their research paper did not report the results of the proposed model and its constructs.

Literature reviews show that few M-learning acceptance studies have been conducted within a K-12 context. Most of these studies investigated teachers' acceptance of M-learning. Several keywords were used to search for acceptance studies conducted within the K-12 context in different databases such as EdITLib, Academic Search Complete, INSPEC, and Google Scholar. As can be seen from the literature, the number of studies conducted within the university context is greater than the K-12 context. No study could be found that had investigated the parameters affecting the adoption of M-learning by pupils in the K-12 Saudi Arabian context.

\section{$3 \quad$ Research hypothesis and model}

This research explored the components affecting the adoption by pupils of M-learning. No research has attempted to address and identify parameters which affect the M-learning adoption by pupils within the K-12 arena in Saudi Arabia, until now. Therefore, a conceptual model was devised to fill this gap.

The research assumptions were based on the UTAUT, which was applied as an anlytical basis for this study. UTAUT was advanced, who demonstrated that it is well suited to demonstrate IT use behavior. The researchers found that the UTAUT model would allow them to explain how and why new technologies found acceptance. Furthermore, they pointed out that testing the model allowed them to discover new constructs, to which prediction of intention to use and behavior could be added. Since the M-learning system is a type of technology (involving software and devices), it was considered highly probable that its acceptance by students could be investigated within a technology acceptance model like UTAUT [45]. 
Earlier research has reported [40] several parameters that could possibly influence the student's acceptance of M-learning in a K-12 context in Saudi Arabia, which pointed to the inclusion of three additional constructs in the model used for research:

- system quality

- hedonic motivation

- learning self-management.

For this research, facilitating circumstances and user behavior were left out of the research, because the researcher was interested in measuring students' behavioral intentions rather than their actual usage of M-learning.

The research model contained seven inherent compositions. A variable's inherent composition cannot be directly measured; however, it can be measured or represented by one or more variables. The variables in this instance were specific items or questions obtained from the participants in the questionnaire. Observed variables are used as indicators of inherent compositions, and these indicators relate to each underlying composition as specified by the researcher.

The research assumptions (i.e., the theoretical framework) consisted of six vital, independent variables, one independent variable, and one moderator (Figure 1).

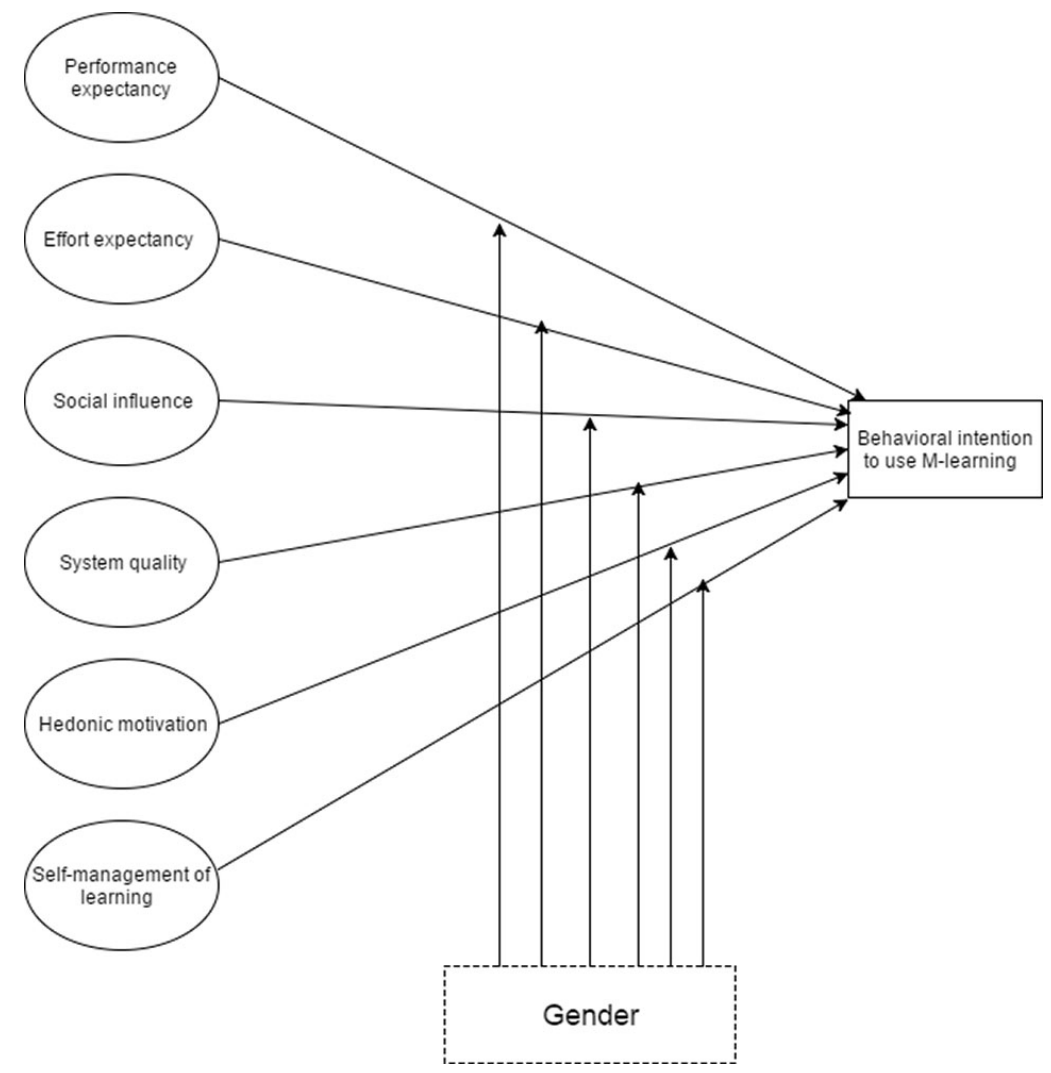

Fig. 1. Research assumption and theoretical framework 
Based on the research model, several hypotheses associated with the constructs were developed and tested.

\subsection{Performance expectancy}

Performance expectancy means the amount to which a particular system is understood to be able to improve employee performance in the workplace. Performance expectancy is also related to other acceptance model constructs like relative advantage (as per IDT), outcome expectations (as per SCT), extrinsic motivation (as per MM), job-fit (as per MPCU), and understanding of how well it can be used (as per TAM/ TAM2 and C-TAMTPB). In the case of tablet computer usage, performance expectancy has been found to be the key determinant in user acceptance, as well as the most common influencer of the degree of adoption. In the current research, performance expectancy was measured in terms of the usefulness, the ability to enhance productivity, and learning outcomes of using M-learning systems. It was also predicted that performance expectancy would impact the strength of feelings that users have towards adopting M-learning. The given hypothesis has been evaluated:

H1: Students' behavioral intention to utilize M-learning will be influenced by performance anticipation.

\subsection{Effort expectancy}

This points to the extent to which a specific system is believed to be convenient and requires little effort to use. It has been acknowledged in other models, including MPCU and TAM, "with regards to its supposed complexity and ease-of-use. It has been found to be a major determinant of IT system acceptance. Along with numerous other researchers, it has also been demonstrated that effort expectancy has a substantial influence on behavioral intention among female users compared to male users, older females more than younger females, and females with less experience more than those with more experience [41-42]. In this research, effort expectancy was measured by measuring the perceptions of the use of M-learning services. The given hypothesis was evaluated:"

H2: Pupils' behavioral intention to employ M-learning would be positively influenced by effort expectancy.

\subsection{Social influence}

Social influence was presented as part of the Ajzen TRA model, wherein it was referred to as "normative beliefs. It has to do with the manner in which behavior is perceived as shaped by peer or societal opinions of the behavior or, in other words, the extent to which other people influence users' acceptance of a system. Social influence was also mentioned in the C-TAM-TPB, TAM2, TPB and other models, where it is referred to in the form of the term 'subjective norm'. Several researchers [43] have discovered that social influence has a direct influence on behavioral intention in terms of technology adoption. Normative beliefs have been broken down into two 
sub forms: peer influence and superior influence. Both forms of normative beliefs were considered as part of social influence in the current study, as per the UTAUT model, wherein social influence was first presented as a single construct. In this study, social influence was measured by the degree to which the perceptions of teachers, peers, and parents affect behavioral intention when it comes to adopting M-learning. Given this, the third hypothesis developed is as follows:

H3: Students' behavioral desire to employ M-learning will be positively influenced by social influence.

\subsection{Hedonic motivation}

The engagement of users in activities using mobile technology can be better understood through an exploration of the factors that motivate them. This is an important consideration for businesses, since this can help to drive sales through being more in tune with the ways in which users are motivated to engage more with smartphones and other mobile technologies for entertainment, academic, and other purposes. As [44] point out, it is likely that long-term engagement and use is positively associated with user satisfaction and perceived value, each of which is linked to motivation. The value mobile device users obtain from using their smartphones and other technologies grows as their level of engagement increases, with such devices allowing them to build and maintain rich, interactive social networks. Users then begin to demonstrate loyalty to their chosen device, which increases their motivation to use the technology whilst also enhancing their satisfaction because of greater value. This, in turn, provides users with even more motivation to engage with their mobile devices.

Hedonic motivation, according to the authors in [44], is described as the enjoyment or satisfaction derived from employing a technology. As explained in initial models, hedonic motivation refers to the perceived enjoyment of a particular system. Researchers such as [46], and [47] have all found that hedonic motivation is a significant element when it comes to new technology being adopted or accepted, whilst also being a reliable indicator of how likely it is for a system to be accepted by users. Additionally, [48] and [49] found that hedonic motivation has a substantial influence on M-learning adoption. The current research incorporated hedonic motivation as a main element in pupils' behavioral intention in terms of them adopting M-learning. Given this, the hypothesis tested is as follows:

H4: Hedonic motivation affects behavioral intention to utilize M-learning in a good way.

\subsection{System quality}

Applied Reeves and Bednar's quality framework to the quality of information systems, asserting that strong performance, software standards, and the use of the latest technology all contribute to superior IS quality. Users obtain value through ease-of-use and usefulness, and developers must also ensure that the software can be updated and maintained easily to avoid user dissatisfaction. The goal of any system must be to both meet the standards set in the industry in which it will be used and fulfil the needs of the end user. 
System quality and information quality have been found to be the two core requirements for the adoption of IS, according to previous research [50]. In the current research, system quality is taken to refer to how clear, accurate, and reliable the overall M-learning system and the services provided by the system are. Users' behavioral willingness to adopt an IS, as well as users' happiness with the IS, have been found to be influenced by system quality [51], and is widely accepted as an influencer of technology acceptance.

Various researchers, including $[52,66]$, have demonstrated that technology acceptance is greatly impacted by system quality, with service and website quality also being noted as important factors. As explained, system quality is an important consideration when studying M-learning as an element of mobile system technology. Moreover, [53] has demonstrated that users' intention to engage with M-learning is positively related to M-learning system quality, as is also the case with E-learning. Therefore, system quality was included in the research model. The overall system quality has been predicted to have a favorable impact on the behavioral intention to utilize M-learning. Given this, the hypothesis tested was as follows:

H5: The quality of the H5 System has a beneficial impact on the behavioral intention to utilize M-learning.

\subsection{Self-management of learning}

This is a type of learning in which learners are allowed to work on real-life problems and projects of their own selection yet are still entitled to learning support in the context of their tasks. Self-directed learning is a vital skill needed in 21 st century education. This learning method raises the intention of students to learn. Since they are the creators of their own learning, they experience responsibility and independence while gaining knowledge. This process keeps them on board, since now they have to gain information and learning independently and apply it along with their innate talents to find answers to their issues, grow their learning, and be encouraged to be life-long learners [54].

Various researchers, including [55] and [56], have highlighted the fact that the self-management of learning is a guide to greater academic attainment, and that higher GPAs have been found amongst students who are more proficient in self-managed learning. Furthermore, self-management of learning has been argued to be a major factor in mobile language learning outcomes for L2 learners [57], finding that English language learners demonstrate higher proficiency when their self-management of learning is more developed.

Interestingly, compared with women, men tend to demonstrate more autonomy in their nature, which could suggest that male learners may be more likely to engage in the self-management of learning through mobile technology. Additionally, it's also been claimed that, as compared to younger learners, older people are more likely to be proficient in self-management. As a result, the inclusion of self-management of learning in this study is beneficial, as it has a direct influence on M-learning acceptability. The following theory was put to the test:

H6: Behavioral intention to utilize M-learning is positively influenced by self-management of learning. 


\section{Questionnaire development and data collection}

\subsection{Instrument development and measures}

Measures that were devised and legitimized by UTAUT underpinned the survey tool employed in this study. Where necessary, measures were adjusted to ensure that they reflected the concept of M-learning used in a high school setting. The researcher undertook the assessment of the measures based on the feedback obtained from two members of the academic staff of Flinders University, and one academic staff member from Jeddah University in Saudi Arabia. The academics also provided feedback for questionnaire refinement. The instrument was modified according to their feedback. Table 1 shows the items used in the study and the literature from which the items were derived:

Table 1. Instrument constructs

\begin{tabular}{|l|c|c|}
\hline \multicolumn{1}{|c|}{ Scale } & No. of Items & Adapted From \\
\hline performance expectancy (PE) & 4 & {$[53,58-60]$} \\
\cline { 1 - 2 } effort expectancy (EE) & 4 & {$[61,62]$} \\
\hline social influence (SI) & 4 & {$[63,64]$} \\
\hline hedonic motivation (HM) & 4 & {$[59,65]$} \\
\hline system quality (SQ) & 4 & {$[57,65,67]$} \\
\hline self-management of learning (SMoL) & 3 & {$[53,58-60,68,69]$} \\
\hline behavioral intention (BI) & 4 & \\
\hline
\end{tabular}

\subsection{Procedures}

For the purposes of data collection, an online questionnaire was created in the second semester of the academic year, October 2015 through the website www.surveymonkey.com. Before the actual data collection process was initiated, data was reported from 272 students at different levels of education. The questionnaire was distributed via an email link to every school that consented to take part in the study. The duration of the survey was around 10 to 15 minutes.

\subsection{Participants}

The population of this study consisted of Saudi students. The survey questionnaire was distributed among Saudi students in Alqassim province, Alrass city. The goal was to validate the study model by looking at the elements that impact high school students' adoption of M-learning in Saudi Arabia.

The online survey was distributed to students at all levels of education, with 295 questionnaires returned. Of the 295 responses, 23 were excluded due to being incomplete. Therefore, the total number of valid responses was 272 , which comprised 139 responses from male students and 133 responses from female students. 


\subsection{Data analysis}

Authors in [70] recommend that researchers lay down data analysis plans in a timely manner, to ensure that the instruments used can collect suitable data. This is significant, as otherwise, data collected may not be relevant to the selected data analysis approach. It is advisable to establish the method of data analysis as early in the research as possible to make sure that the chosen tools of data collection can extract the necessary data [70]. The outcomes of the chosen method of data analysis will not be relevant if the data is unsuitable. Data analysis was performed with two statistical instruments in this study. The software program SPSS (Version 22) was initially used to produce descriptive statistics that indicated the frequency, proportion, and accumulative percent of participant characteristics, as well as to determine how reliable the data were (Cronbach's alpha). Data was analyzed to confirm or reject the hypotheses relating to the various relationships in the proposed model. The viability of the assumptions connected to various interactions in the model was then assessed using structural equation modeling (SEM). Model validation has been performed by numerous studies with the help of SEM or multiple regression and path analysis, both of which are incorporated into SEM [71, 72].

\section{$5 \quad$ Measurement models}

The results for the measurement model are shown in Table 2. The measurement model was drawn using AMOS software version 22 which presents more than 20 different goodness-of-fit measures. As can be seen in Table 2, the goodness-of-fit indices achieved acceptable results. A significant Chi-square implies that the model does not account for the data, whereas a non-significant Chi-square (i.e., p value $>0.05$ ) provides model support. Furthermore, the Chi-square statistic was supplemented by other varied tests (identified in section 5.6) of fit in order to gain a consensus on the applicability of the model. Table 2 presents the main fit statistics applied and their acceptable levels.

Table 2. Results of the measurement model

\begin{tabular}{|c|c|c|c|c|c|c|c|}
\hline Chi-sq. & p-value & cmin/df & rmsea & gfi & agfi & cfi & pratio \\
\hline 236.795 & 0.091 & 1.133 & 0.022 & 0.933 & 0.911 & 0.988 & 0.826 \\
\hline
\end{tabular}

\subsection{Validity analysis}

The validity of the constructs had to be confirmed before applying the independent and dependent constructs to the structural model and testing the hypotheses. Construct validity has to do with the degree to which measured variables reflect the construct. Typically, it involves calculating two subdivisions: convergent and discriminant validity [70]. A few measures are necessary to calculate the discriminant and convergent legitimacy of the constructs. These are maximum shared variance (MSV), average shared variance (ASV) and average variance extracted (AVE). 
Authors in [70] explain that convergent validity refers to the assertion that all items associated with a construct should have a common degree of variance. Convergent validity, according to Straub and Boudreau, is the degree to which items are indicative of a single construct, with defining convergent validity as the degree of correlation between a research instrument and theoretically relevant constructs and scales. Poor correlation between the chosen variables is indicated by convergent validity problems, meaning that the variables do not offer a good level of insight into the latent factor associated with them.

The CR, MSV, AVE, and ASV, along with composite reliability, can be found in Table 3. Here, we can see that all composite reliabilities for each factor exceeded the criterion of 0.70 . Furthermore, all factors demonstrated discernment validity, which indicates that no constructs of a factor in the model had any effect on other constructs of other factors in the same model. However, one component (self-management of learning) has a convergent validity issue, as shown in Table 3, because the AVE was less than the suggested threshold value of 0.50 . Therefore, the researcher had to further investigate this problem, as both CR and the discriminant validity of self-management of learning were accepted. The researcher found that the question that was asked to determine the self-management of the learning factor was sometimes misinterpreted by the participants. The variables for self-management of learning have mixed responses, which somewhat contradict the qualitative responses. Because the students misinterpreted and mixed these variables, the convergent validity for these constructs was below the threshold. As a result, one item, SMoL3, was dropped from the study and no validity issues were found after eliminating that item.

Table 3. Validity results (CR, MSV, AVE and ASV)

\begin{tabular}{|l|c|c|c|c|}
\hline & CR & AVE & MSV & ASV \\
\hline HM & 0.808 & 0.684 & 0.508 & 0.195 \\
\hline PE & 0.849 & 0.585 & 0.329 & 0.193 \\
\hline EE & 0.795 & 0.565 & 0.345 & 0.175 \\
\hline SQ & 0.776 & 0.537 & 0.329 & 0.132 \\
\hline SI & 0.757 & 0.517 & 0.007 & 0.004 \\
\hline SMoL & 0.705 & 0.454 & 0.051 & 0.017 \\
\hline BI & 0.807 & 0.512 & 0.508 & 0.242 \\
\hline
\end{tabular}

The square correlation shared by any two constructs was smaller than their individual AVE, as seen in Table 4. After eliminating SMoL3 from the research, all validity and reliability checks revealed that the CFA model was verified, and these constructs could be securely put into the structural model analysis. 
Table 4. Factor correlation matrix with square root of the AVE on the diagonal for the exogenous and endogenous constructs

\begin{tabular}{|l|c|c|c|c|c|c|c|}
\hline & SMoL & PE & EE & SQ & HM & SI & BI \\
\hline SMoL & 0.742 & & & & & & \\
\hline PE & 0.120 & 0.765 & & & & & \\
\hline EE & 0.082 & 0.523 & 0.752 & & & & \\
\hline SQ & 0.062 & 0.574 & 0.335 & 0.733 & & & \\
\hline HM & 0.152 & 0.471 & 0.557 & 0.322 & 0.764 & & \\
\hline SI & 0.044 & 0.061 & 0.071 & 0.086 & 0.039 & 0.719 & \\
\hline BI & 0.227 & 0.558 & 0.587 & 0.488 & 0.713 & 0.036 & 0.715 \\
\hline
\end{tabular}

\section{The structural model}

Following the successful construction of the measurement model, the next stage was to create a structural model that included all six components. A structural model shows the relationships that exist between various variables. According to [73], structural models are statistical methods designed with hypothesis testing in mind when assessing a structural theory relevant to a particular research topic or object.

[70] demonstrate that hypothesis assessment is used to assess if a hypothesis makes a significant contribution to the interpretation of the dependent variables. Exogenous (independent) variables included performance expectancy, effort expectancy, social impact, enabling circumstances, and system quality, while endogenous (dependent) factors included behavioral intention.

An examination of model fit indicators was part of the structural model evaluation (like those used in the measurement model). The standardized path coefficients and critical ratio (t-values) were also examined in the structural model to see if the hypothesized correlations were confirmed or not. The crucial ratio ought to be greater than \pm 1.96 (significant at alpha $(\alpha)$ level 0.05 ) or \pm 2.56 (significant at alpha $(\alpha)$ level 0.01 ) to evaluate if the postulated association is substantial.

\subsection{Results of the structural model}

"In SEM, the structural model tested the estimated path coefficients, t-values (critical ratio), and standard errors, to evaluate the relationships and decide regarding the hypotheses. Figure 2 presents the SEM outputs and depicts a graphic representation of the structural model showing the results of the hypothesis testing. However, for better understanding, the results are also presented in Table 5. As can be seen from Table 5, the findings showed that the performance expectancy (PE) construct positively predicted the behavioral intention (BI) construct $(\beta=0.172, p<0.05)$, thus supporting $\mathrm{H} 1$. Secondly, effort expectancy (PE) positively predicted behavioral intention (BI) $(\beta$ $=0.267, \mathrm{p}<0.05)$; therefore, H2 was supported. Thirdly, social influence (SI) did not significantly predict behavioral intention $(\beta=-0.022 \mathrm{p}>0.05)$; therefore, $\mathrm{H} 3$ was not supported. Fourthly, hedonic motivation (HM) positively predicted behavioral intent 
$(\beta=0.533 \mathrm{p}<0.05)$; therefore, H4 was supported. Fifthly, system quality (SQ) positively predicted behavioral intention $(\beta=0.245 \mathrm{p}<0.05)$; therefore, H5 was supported; and finally, self-management of learning $(\mathrm{SMoL})$ positively predicted behavioral intent $(\beta=0.146 \mathrm{p}<0.05)$, thus providing support for H6. Hedonic motivation was found to be the most influential predictor of M-learning acceptance $(\beta=0.533)$, and self-management of learning was found to be the lowest influential predictor of M-learning ( $\beta$ $=0.146$ ). The model accounts for $52 \%$ of the variance in behavioral intention to use M-learning."

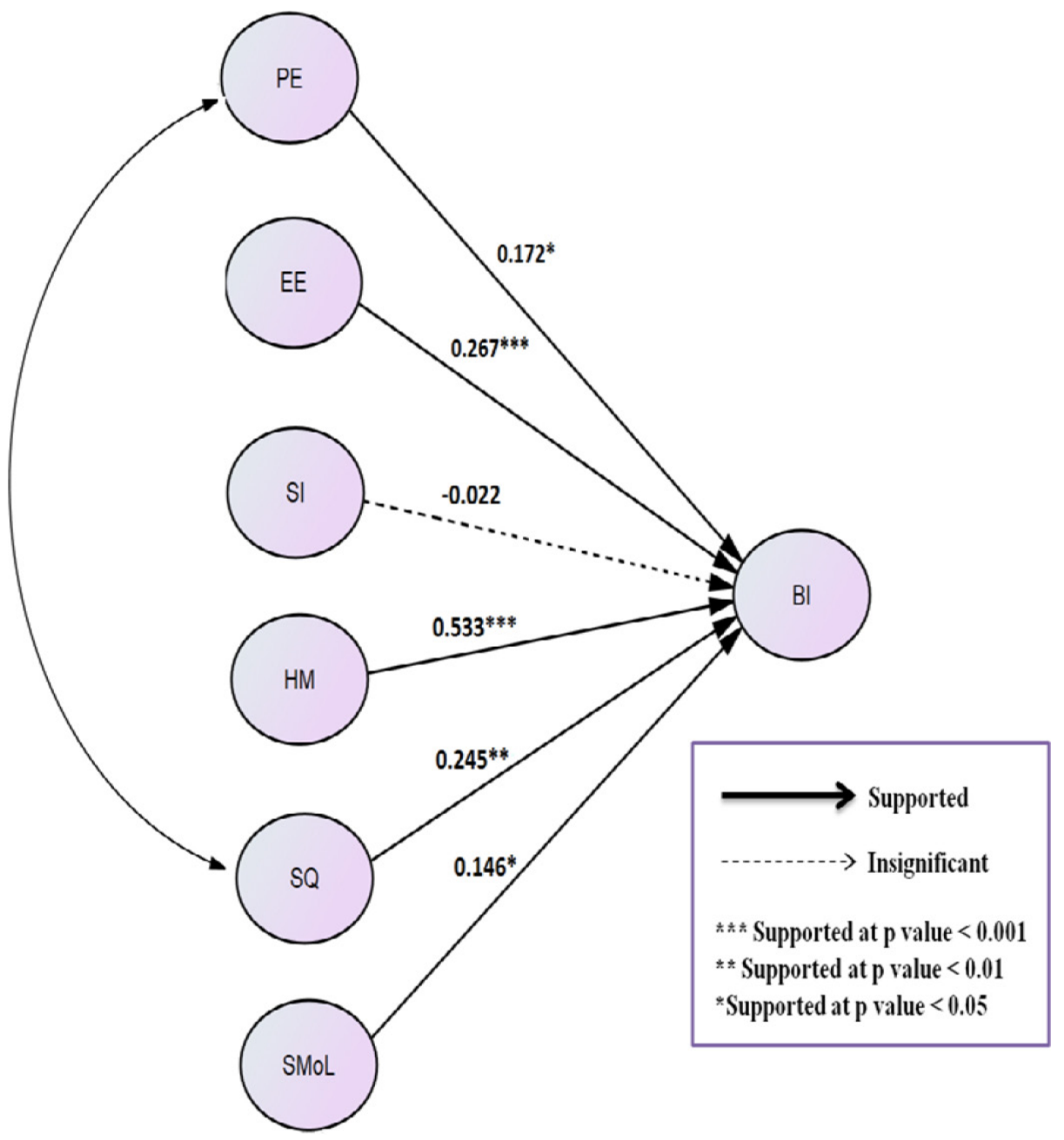

Fig. 2. Structural model results 
Table 5. Structural model results

\begin{tabular}{|l|c|c|c|c|}
\hline \multicolumn{1}{|c|}{ Hypothesis } & $\begin{array}{c}\text { Standardized Path } \\
\text { Coefficient }\end{array}$ & $\begin{array}{c}\text { Critical Ratio } \\
\text { (t-value) }\end{array}$ & P Value & $\begin{array}{c}\text { Empirical } \\
\text { Support }\end{array}$ \\
\hline $\mathrm{H} 1: \mathrm{PE} \rightarrow \mathrm{BI}$ & 0.172 & 2.043 & .041 & Accepted \\
\hline $\mathrm{H} 2: \mathrm{EE} \rightarrow \mathrm{BI}$ & 0.267 & 3.879 & $* * *$ & Accepted \\
\hline $\mathrm{H} 3: \mathrm{SI} \rightarrow \mathrm{BI}$ & -0.022 & -0.345 & 0.730 & Rejected \\
\hline $\mathrm{H} 4: \mathrm{HM} \rightarrow \mathrm{BI}$ & 0.533 & 6.603 & $* * *$ & Accepted \\
\hline $\mathrm{H} 5: \mathrm{SQ} \rightarrow \mathrm{BI}$ & 0.245 & 2.752 & 0.006 & Accepted \\
\hline $\mathrm{H} 6: \mathrm{SMoL} \rightarrow \mathrm{BI}$ & 0.146 & 2.066 & 0.039 & Accepted \\
\hline
\end{tabular}

Note: Any P value less than 0.001 was designated with three $(* * *)$ asterisks.

\subsection{Moderator effect}

The investigation of whether the influence of determinants (PE, EE, HM, SQ, and $\mathrm{SMoL}$ ) toward behavior intention (BI) was moderated by gender was performed by testing the following moderating hypothesis which stated that: The influence of determinants (PE, EE, HM, SQ, and SMoL) toward behavioral intention (BI) is moderated by gender. In other words, the direct paths between determinants and behavioral intention differed between males (139 cases) and females (133 cases).

Checking the fit indices simultaneously (for both groups) resulted in the following fit statistics: Chi-sq $=630.297 ; \mathrm{P}$-value $=.000 ; \mathrm{CMIN} / \mathrm{df}$ ratio $=1.560 ; \mathrm{CFI}=.899$; $\mathrm{RMSEA}=.046$; GFI $=0.835$; $\mathrm{AGFI}=0.793$; PRATIO $=0.874$. The results demonstrated acceptable fit indices for CMIN/df, RMSEA and PRATIO. However, the values of GFI, AGFI and CFI were below the recommended amounts.

Testing for moderation influence included constraining each path separately while the other paths were estimated freely [74]. For example, to test the path $\mathrm{PE} \rightarrow \mathrm{BI}$, the path was constrained to be equal across males and females, while all other paths were estimated freely. Five paths were tested separately. Table 6 shows the result of the Chisquare test in AMOS for every path in the model.

Table 6. Moderation results

\begin{tabular}{|l|l|c|c|c|}
\hline \multicolumn{1}{|c|}{ Path } & \multicolumn{1}{c|}{ Model } & DF & CMIN & p-value \\
\hline $\mathrm{PE} \rightarrow \mathrm{BI}$ & Structural weights & 1 & 0.017 & 0.896 \\
\hline $\mathrm{EE} \rightarrow \mathrm{BI}$ & Structural weights & 1 & 0.044 & 0.833 \\
\hline $\mathrm{HM} \rightarrow \mathrm{BI}$ & Structural weights & 1 & 0.088 & 0.767 \\
\hline $\mathrm{SQ} \rightarrow \mathrm{BI}$ & Structural weights & 1 & 0.782 & 0.376 \\
\hline $\mathrm{SMoL} \rightarrow \mathrm{BI}$ & Structural weights & 1 & 0.666 & 0.415 \\
\hline
\end{tabular}

The multi-group analysis results showed that gender had no significant effect on the relationships among constructs in the proposed model. Thus, it could be concluded that the moderator hypotheses were rejected. Consequently, the direct paths from determinants (PE, EE, HM, SQ, and SMoL) toward behavioral intention (BI) did not differ in magnitude and/or direction for males and females. 


\section{Discussion}

This study used a theoretical model grounded in the UTAUT, which was amended to exclude facilitating conditions and use behavior, while it included three additional factors (i.e., hedonic motivation, system quality and self-management of learning) that had emerged from the responses received from conducting a previous study on M-learning in public schools in Saudi Arabia [31, 40]. The UTAUT model in this research was closely examined to identify the effect of its constructs on adoption and usage of M-learning in Saudi Arabian high schools. Each factor is discussed separately to explain the results of hypothesis testing. The results of the relationship between the UTAUT model and the hypotheses are discussed below.

According to the results of the present research, expectancy of performance has a beneficial impact on behavioral intent. $\left(b^{*}=0.172, p<0.05\right)$. The finding is also supported by some empirical studies that investigated M-learning [75-76]. This shows that how useful M-learning appears to be has a link with how easily or eagerly pupils will adopt it. In other words, it appears that pupils who have a higher expectancy from performance and trust that M-learning will be helpful and enhance their learning, tend to acknowledge it more, as opposed to the opposite. If the benefits of using M-learning were demonstrated to the students in an interactive manner, the acceptance and use of M-learning would most likely increase.

Like performance expectancy, in this present research, The link between effort expectation and behavioral intention was shown to be substantial, indicating that students are more likely to acquire a favorable attitude about M-learning if they feel it would take minimal effort or time to learn and utilize $\left(b^{*}=0.267, p<0.001\right)$. Furthermore, this positive relationship could be supported by designing and implementing simple, easy to use M-learning apps to attract students to the use of such technologies [77]. This statistically significant influence suggests that students are apt to deploy M-learning since it is easier to utilize, which includes providing quality services and the procedures and instructions needed to use M-learning tools. Moreover, more technical considerations are needed to provide intuitive and comparable applications for different types of mobile devices for use by different students (including students with special needs) to enhance their M-learning experience.

In the present research, however, the social effect on behavioral intention to utilize M-learning was revealed to be an unimportant predictor $\left(b^{*}=-0.022, p>0.05\right)$. The current study's findings imply that students are not socially influenced by their peers or teachers to use M-learning, which comes as no surprise considering the administrative constraints in the Saudi Arabian context. The Ministry of Education in Saudi Arabia standardized and regulated classroom instruction, and each grade level was given a uniform curriculum with standards and timelines that they were expected to implement and obey [78]. This finding concurs with previous studies undertaken in the Saudi Arabian context, which had shown the insignificance of social influence when it came to technology acceptance.

For example, the UTAUT model was used by [79] to look at the elements that impact the adoption of M-commerce. Their findings showed that social influence was not relevant to users' behavioral intention to use M-commerce. Likewise, alongside other factors, [65] investigated the impact of social influence on the adoption of E-government 
in Saudi Arabia. They found that social influence was the only insignificant factor, indicating that the use of E-government systems is a personal and self-affected topic and not affected by social effects. Another study, but with different inputs, by [80] investigated six factors, including social influence, that impacted M-learning adoption in Malaysia. Four hundred students from four technical universities engaged in the study. Social influences did not have a significant influence on the intention to utilize M-learning behaviorally, according to the findings. The premise that societal outlooks would have a significant impact on intention was rejected, as were the outcomes of this study. The findings of the present research indicate that the adoption of M-learning in Saudi Arabian high schools is contingent on the student's confidence, ability, and self-esteem, which all affect their capacity to deal with a technological system, rather than the opinions and beliefs of others. The evidence strongly suggests that the use of M-learning among students is regarded as a personal and self-centered issue that is unaffected by the perspectives of others. It can be concluded that in Saudi Arabia, where M-learning implementation is still considered to be in its early stages, the use of M-learning among high school students is not affected by peers, teachers, or school.

Authors in [81] found hedonic motivation had a positive effect on behavioral goal setting, and they recommended that the manufacturers of smart wearable devices design their products in a way that was pleasant, beneficial, and fun. Furthermore, [82] investigated the role of hedonic motivation and other constructs in the acceptance by medical staff of the use of an electronic health record (EHR) system in hospitals. Their results showed that hedonic motivation had a sizable influence on the usage of the electronic health record.

According to the findings of the current research, hedonic motivation did have a significant part to play for pupils in terms of their M-learning adoption $\left(b^{*}=0.533\right.$, $p<0.001)$. The findings demonstrated that pupils in high schools are willing to use such technologies if fun and pleasure are associated with them. M-learning tools often provide many entertaining and interactive functions that offer enjoyment and a sense of satisfaction. M-learning apps should be designed to include a range of motivational and pleasurable features that enhance a student's engagement in the process of learning. This factor is consistent with other M-learning research that included perceived enjoyment, playfulness, or hedonic motivation in their research models, such as [49, 83, 84].

System quality was reported in several studies as a crucial factor that directly affects the goal of using e-applications in general. Similarly, the findings of this research indicate that system quality has a beneficial influence on behavioral intentions to utilize M-learning $\left(b^{*}=0.245, p<0.01\right)$. This conclusion is backed up by number of empirical investigations that have looked into M-learning. [85, 86]. The results of the present research indicate that students can benefit from better communication, shorter response times, greater privacy, and greater convenience when the quality of the system used is high. Without a certain standard of system quality, M-learning system efficiency cannot be achieved since students will not perceive the system to be appealing. For this reason, it is important for systems to be designed with two specific considerations in mind. First, the system features should be easy to use, with particular emphasis on network speed, navigation speed, response time, integration, flexibility, and the user interface design. Second, feedback and input from students, teachers, and researchers must be attained to develop the most useful and successful system possible. 
Self-management of learning has been shown to be an indicator as to whether an individual is likely to accept M-learning $\left(b^{*}=0.146, p<0.05\right)$. The greater autonomy a student displays in their engagement with education, the more likely they are to use M-learning $[87,88]$. The present research demonstrates the accuracy of the self-management of learning parameters as put forward by Al-Adwan, Al-Adwan [89], which predicts the aim of an individual to use M-learning. This test is useful to M-learning practitioners and system developers in giving them the ability to decide how they can motivate students. This may be done by building applications such as learning content hierarchy control and time management systems into the M-learning apps to appeal to those with a good attitude to the self-management of learning. In addition, functions could be built in to develop an individual's capacity for self-motivation. Educators should encourage life-long learning and self-betterment, which will in turn increase engagement with M-learning in the future.

The findings of this study align with those of $[90,91]$, observing that no substantial variance between the sexes existed when it comes to using mobile technologies in their learning activities. Differences between males and females in using technology are perennially a topic of research interest. It is important to understand the repetitive behavior among genders, including behavioral intention toward and beliefs about ICT, as such awareness would provide a better grounding for design and implementation, which would offer greater opportunities to support ICT success in education and other contexts. The variety of beliefs held by different genders would likely have a reciprocal influence on the intent to utilize a given technology in the future.

Mobile technologies have become increasingly popular in recent years. With the features and capabilities of smartphones, they have gained a huge popularity with teenagers in different places around the world. In Saudi Arabia, like any other digital nation, teenagers and adults have turned to the virtual terrain to socialize, play games, learn, and connect with fellow netizens scattered across the globe.

According to a technical report about mobile devices in the Middle East [91], 79\% of Saudi Arabia's population use an advanced handset. Despite collecting the data from three female schools compared with five male schools in this study, the analysis showed that almost half of respondents in the study were females, and all participants (including males and females) possessed a smart mobile device. This indicates that females in Saudi Arabia, like males, are strongly interested in using mobile technologies, and confident in using them in their learning and study activities.

\section{Conclusion and potential implications for K-12 education}

The research provides information to Saudi Arabian decision-makers who are contemplating implementing digital technology in K-12 schools. By examining the different elements studied in this research, as well as the consequences, the data can assist decision makers in formulating and devising particular plans and practices for successful deployment of M-learning. According to Saudi Vision 2030 [93], over the next few years, the Saudi Arabian Ministry of Education is planning to encourage acceptance of innovation, as well as resources and attempts to improve the education sector. M-learning must be considered by Ministry of Education decision-makers for its 
significant gains. The adoption of M-learning is expected to deliver benefits by increasing productivity and collaboration between students. With a clearer outlook on the critical factors in M-learning being accepted, the Ministry of Education can effectively manage M-learning diffusion and implementation in schools. An educational use for mobile phones has the potential to improve educational outcomes, while providing a powerful repository for scholarship activity.

In this study, the students were positively influenced mainly by their perceptions of the potential positive aspects of M-learning and its expected simplicity, based on the significant influence of performance expectancy on its acceptance. Therefore, the Ministry of Education and the policy makers should emphasize the issues that would improve student performance academically using M-learning applications. An M-learning system, whether it be a mobile app for learning different subjects or a learning management system (LMS), for example Mobile Blackboard, should facilitate student learning. But the system needs to be genuinely useful for learning and teaching, improving students' results, productivity, collaboration, and efficiency.

Furthermore, the Ministry of Education should focus on aspects of M-learning that make it easy to use. All students, including those with special needs, should be able to successfully use the system with minimum effort. Students will be looking for an M-learning system that offers fast implementation, is quick to learn, and provides support and training materials. An M-learning educational methodology should be accessible enough for students to try with success so that they can discover its usefulness as a learning tool and use it with confidence for that purpose.

According to the research findings and previous studies, fun elements added to a learning app have played a pivotal role in user technology acceptance, which indicates that enjoyment derived from usage directly drives continuous engagement with the mobile system [93]. Given that user enjoyment of mobile systems directly impacts behavioral intention, it is essential that student enjoyment of M-learning systems is considered a top priority by software developers who design M-learning systems in Saudi Arabia.

Whether it is entertaining or not, if the learning app is poorly designed, it will frustrate and anger students, who will eventually abandon the software, often after considerable time and money have been spent. A detailed plan of project specifications, design, frameworks, and programming languages to be used, testing, and maintenance will help to produce quality apps and reduce the possibility of errors (system bugs). Developing high-quality software apps may not be cheap. However, it is less costly than creating an inferior quality one. The issue, of course, for schools that want to introduce M-learning, is investing in the best apps.

Even with well-chosen applications and appropriate technology, the results of this research indicate that it will be learners who are better able to apply self-management of learning who will achieve better mobile learning results. It is beneficial to these students that they be encouraged to participate in M-learning so they can achieve better learning outcomes, since they will be able to pace themselves. 


\section{$9 \quad$ References}

[1] Ally, M., \& J. Prieto-Blázquez, What is the future of mobile learning in education? International Journal of Educational Technology in Higher Education, 2014. 11(1): p. 142-151.

[2] Almaiah, M.A., \& O.A. Alismaiel, Examination of factors influencing the use of mobile learning system: An empirical study. Education and Information Technologies, 2019. 24(1): p. 885-909. https://doi.org/10.1007/s10639-018-9810-7

[3] Alrasheedi, M., \& L.F. Capretz, Determination of critical success factors affecting mobile learning: A meta-analysis approach. arXiv preprint arXiv:1801.04288, 2018.

[4] Kivunja, C., Do you want your students to be job-ready with 21 st Century skills? Change pedagogies: A pedagogical paradigm shift from Vygotskyian social constructivism to critical thinking, problem solving and Siemens' Digital Connectivism. International Journal of Higher Education, 2014. 3(3): p. 81-91. https://doi.org/10.5430/ijhe.v3n3p81

[5] Rich, E., \& A. Miah, Mobile, wearable and ingestible health technologies: towards a critical research agenda. Health Sociology Review, 2017. 26(1): p. 84-97. https://doi.org/10.1080/ 14461242.2016 .1211486

[6] Fu, Q.-K., \& G.-J. Hwang, Trends in mobile technology-supported collaborative learning: A systematic review of journal publications from 2007 to 2016. Computers \& Education, 2018. 119: p. 129-143. https://doi.org/10.1016/j.compedu.2018.01.004

[7] Bartholomew, S.R., et al., Relationships between access to mobile devices, student self-directed learning, and achievement. Journal of Technology Education, 2017. 29(1): p. 2. https://doi.org/10.21061/ite.v29i1.a.1

[8] Christensen, R., \& G. Knezek, Readiness for integrating mobile learning in the classroom: Challenges, preferences and possibilities. Computers in Human Behavior, 2017. 76: p. 112-121. https://doi.org/10.1016/j.chb.2017.07.014

[9] Alhassan, R., Mobile learning as a method of ubiquitous learning: Students' attitudes, readiness, and possible barriers to implementation in higher education. Journal of Education and Learning, 2016. 5(1): p. 176-189. https://www.nyt imes.com/2020/04/28/world/europe/ coronavirus-Greece-europe.html; https://doi.org/10.5539/jel.v5n1p176

[10] Palpanadan, S.T., Ahmad, I., \& Subramaniam, T.S.A., Malaysian undergraduates' perceptions of online approach via Skype in developing speaking skills. International Journal of Interactive Mobile Technologies (iJIM), [S.1.], 2021. 15(18): p. 168-177. ISSN 1865-7923. https://doi.org/10.3991/ijim.v15i18.24543

[11] Rosman, M.R.M., et al., User behavioral intention to use online distance learning (ODL): The role of self-efficacy and domain knowledge. International Journal of Interactive Mobile Technologies (iJIM), [S.1.], 2021. 15(18): p. 4-15. ISSN 1865-7923. https://doi.org/10.3991/ ijim.v15i18.24539

[12] Kallou, S., \& Kikilia, A., A transformative educational framework in tourism higher education through digital technologies during the COVID-19 pandemic. Advances in Mobile Learning Educational Research, 2021. 1(1): p. 37-47. https://doi.org/10.25082/AMLER.2021.01.005

[13] Karakose, T., Yirci, R., \& Papadakis, S., Exploring the interrelationship between COVID19 Phobia, work-family conflict, family-work conflict, and life satisfaction among school administrators for advancing sustainable management. Sustainability, 2021. 13(15): p. 8654. https://doi.org/10.3390/su13158654

[14] Karakose, T., Yirci, R., Papadakis, S., Ozdemir, T.Y., Demirkol, M., \& Polat, H., Science mapping of the global knowledge base on management, leadership, and administration related to COVID-19 for promoting the sustainability of scientific research. Sustainability, 2021. 13(17): p. 9631. https://doi.org/10.3390/su13179631 
[15] Maru, M.G., et al., The internet use for autonomous learning during COVID-19 pandemic and its hindrances. International Journal of Interactive Mobile Technologies (iJIM), [S.1.], 2021. 15(18): p. 65-79. ISSN 1865-7923. https://doi.org/10.3991/ijim. v15i18.24553

[16] Van, N.T., et al., Digital readiness for social educators in health care and online learning during COVID-19 pandemic: A bibliometric analysis. International Journal of Interactive Mobile Technologies (iJIM), [S.1.], 2021. 15(18): p. 104-115. ISSN 1865-7923. https://doi. org/10.3991/ijim.v15i18.25529

[17] Ong, M.H.A., Yasin, N.M., \& Ibrahim, N.S., Immersive experience during Covid-19: The mediator role of alternative assessment in online learning environment. International Journal of Interactive Mobile Technologies (iJIM), [S.1.], 2021. 15(18): p. 16-32. ISSN 1865-7923. https://doi.org/10.3991/ijim.v15i18.24541

[18] Kalogiannakis, M., \& Papadakis, S., Combining mobile technologies in environmental education: A Greek case study. International Journal of Mobile Learning and Organisation, 2017. 11(2), p. 108-130. https://doi.org/10.1504/IJMLO.2017.10005249

[19] Poultsakis, S., Papadakis, S., Kalogiannakis, M., \& Psycharis, S., The management of Digital Learning Objects of Natural Sciences and Digital Experiment Simulation Tools by teachers. Advances in Mobile Learning Educational Research, 2021. 1(2), p. 58-71. https://doi. org/10.25082/AMLER.2021.02.002

[20] Papadakis, S., Kalogiannakis, M., \& Zaranis, N., Teaching mathematics with mobile devices and the Realistic Mathematical Education (RME) approach in Kindergarten. Advances in Mobile Learning Educational Research, 2021. 1(1), p. 5-18. https://doi.org/10.25082/ AMLER.2021.01.002

[21] Papadakis, S., Kalogiannakis, M., Sifaki, E., \& Vidakis, N., Access moodle using smart mobile phones. A case study in a Greek University. In Interactivity, Game Creation, Design, Learning, and Innovation, 2017. 376-385. https://doi.org/10.1007/978-3-319-76908-0 36

[22] Papadakis, S., Kalogiannakis, M., Sifaki, E., \& Vidakis, N., Evaluating Moodle use via Smart Mobile Phones. A case study in a Greek University. EAI Endorsed Transactions on Creative Technologies, 2018. 5(16). https://doi.org/10.4108/eai.10-4-2018.156382

[23] Papadakis, S., Vaiopoulou, J., Sifaki, E., Stamovlasis, D., Kalogiannakis, M., \& Vassilakis, K., Factors That Hinder In-Service Teachers from Incorporating Educational Robotics into Their Daily or Future Teaching Practice. In B. Csapo and J. Uhomoibhi (Eds). Proceedings of the 13th International Conference on Computer Supported Education (CSEDU 2021), 2021. 2: p. 55-63. https://doi.org/10.5220/0010413900550063

[24] Papastergiou, M., \& Mastrogiannis, I., Design, development and evaluation of open interactive learning objects for secondary school physical education. Education and Information Technologies, 2021. 26(3): p. 2981-3007. https://doi.org/10.1007/s10639-020-10390-2

[25] Sotirova, E.M., Primary School Teacher's Practices and Student's Mental Representations: The Learning Objects option. European Journal of Open Education and E-learning Studies, 2020. 5(2): p. 91-101. https://doi.org/10.46827/ejoe.v5i2.3327

[26] Redmond, C., Davies, C., Cornally, D., Adam, E., Daly, O., Fegan, M., \& O'Toole, M., Using reusable learning objects (RLOs) in wound care education: Undergraduate student nurse's evaluation of their learning gain. Nurse Education Today, 2018. 60: p. 3-10. https:// doi.org/10.1016/j.nedt.2017.09.014

[27] Tzagkaraki, E., Papadakis, S., \& Kalogiannakis, M., Exploring the Use of Educational Robotics in primary school and its possible place in the curricula. In M. Malvezzi, D. Alimisis, \& M. Moro (Eds). Education in \& with Robotics to Foster 21st Century Skills. Proceedings of EDUROBOTICS 2020, Online Conference February, 25-26, 2021. p. 216-229. https://doi.org/10.1007/978-3-030-77022-8 19 
[28] Aprea, C., \& A. Cattaneo, Designing technology-enhanced learning environments in vocational education and training. The Wiley handbook of vocational education and training, 2019. p. 373-393. https://doi.org/10.1002/9781119098713.ch19

[29] Liu, Y., et al., An empirical investigation of mobile government adoption in rural China: A case study in Zhejiang province. Government Information Quarterly, 2014. 31(3): p. 432-442. https://doi.org/10.1016/j.giq.2014.02.008

[30] Lin, C.P., L.H. Wong, \& Y.J. Shao, Comparison of 1: 1 and 1: m CSCL environment for collaborative concept mapping. Journal of Computer Assisted Learning, 2012. 28(2): p. 99-113. https://doi.org/10.1111/j.1365-2729.2011.00421.x

[31] Oyaid, A.A., Secondary student's perceptions of information and communication technology and their usage of it inside and outside of school in Riyadh City, Saudi Arabia. International Journal of Applied Educational Studies, 2010. 7(1).

[32] Alkhalaf, A., Identifying mobile learning challenges at male high schools in Saudi Arabia from the teachers point of view. International Journal of Learning and Teaching, 2014. 6(1).

[33] Holden, H., \& R. Rada, Understanding the influence of perceived usability and technology self-efficacy on teachers' technology acceptance. Journal of Research on Technology in Education, 2011. 43(4): p. 343-367. https://doi.org/10.1080/15391523.2011.10782576

[34] AlShammari, I.A., High School Principals' Attitudes toward the Implementation of E-administration in Kuwait's Public Schools. 2015.

[35] Lin, M.-F., et al., Possibilities and challenges in mobile learning for K-12 teachers: a pilot retrospective survey study. in 2012 IEEE Seventh International Conference on Wireless, Mobile and Ubiquitous Technology in Education. 2012. IEEE. https://doi.org/10.1109/ WMUTE.2012.31

[36] Lin, H.-H., et al., Measuring mobile learning readiness: scale development and validation. Internet Research, 2016. https://doi.org/10.1108/IntR-10-2014-0241

[37] Osakwe, J., N. Dlodlo, \& N. Jere, Where learners' and teachers' perceptions on mobile learning meet: A case of Namibian secondary schools in the Khomas region. Technology in Society, 2017. 49: p. 16-30. https://doi.org/10.1016/j.techsoc.2016.12.004

[38] Ali, R.A. \& M.R.M. Arshad, Perspectives of students' behavior towards mobile learning (M-learning) in Egypt: an extension of the UTAUT model. Engineering, Technology \& Applied Science Research, 2016. 6(4): p. 1109-1114. https://doi.org/10.48084/etasr.710

[39] Alkhalifah, T. Students' perceptions and attitudes towards mobile learning in the K-12 context in Saudi Arabia. in 2018 International Conference on eCommerce, e-Administration, e-Society, e-Education, and e-Technology. 2018. Osaka, Japan.

[40] Wang, H., et al., Understanding consumer acceptance of healthcare wearable devices: An integrated model of UTAUT and TTF. International Journal of Medical Informatics, 2020. p. 104156. https://doi.org/10.1016/j.ijmedinf.2020.104156

[41] Lee, J.-M., B. Lee, \& J.-Y. Rha, Determinants of mobile payment usage and the moderating effect of gender: Extending the UTAUT model with privacy risk. International Journal of Electronic Commerce Studies, 2019. 10(1): p. 43-64. https://doi.org/10.7903/ijecs.1644

[42] Zhou, L.L., et al., Assessment of the social influence and facilitating conditions that support nurses' adoption of hospital electronic information management systems (HEIMS) in Ghana using the unified theory of acceptance and use of technology (UTAUT) model. BMC Medical Informatics and Decision Making, 2019. 19(1): p. 230. https://doi.org/10.1186/ s12911-019-0956-Z

[43] Wachter, K., Y.H. Kim, \& M. Kim, Mobile users: Choosing to engage. International Journal of Sales, Retailing and Marketing, 2012. 1(1): p. 3-13.

[44] Venkatesh, V., J.Y. Thong, \& X. Xu, Consumer acceptance and use of information technology: extending the unified theory of acceptance and use of technology. MIS Quarterly, 2012. p. 157-178. https://doi.org/10.2307/41410412 
[45] Madigan, R., et al., What influences the decision to use automated public transport? Using UTAUT to understand public acceptance of automated road transport systems. Transportation Research Part F: Traffic Psychology and Behaviour, 2017. 50: p. 55-64. https://doi. org/10.1016/j.trf.2017.07.007

[46] Raza, S.A., N. Shah, \& M. Ali, Acceptance of mobile banking in Islamic banks: evidence from modified UTAUT model. Journal of Islamic Marketing, 2019. https://doi.org/10.1108/ JIMA-04-2017-0038

[47] Kumar, J.A., \& B. Bervell, Google Classroom for mobile learning in higher education: Modelling the initial perceptions of students. Education and Information Technologies, 2019. 24(2): p. 1793-1817. https://doi.org/10.1007/s10639-018-09858-Z

[48] Moorthy, K., et al., Habit and hedonic motivation are the strongest influences in mobile learning behaviours among higher education students in Malaysia. Australasian Journal of Educational Technology, 2019. 35(4). https://doi.org/10.14742/ajet.4432

[49] Amalia, F., The Used of Modified UTAUT 2 Model to Analyze The Continuance Intention of Travel Mobile Application in 2019 7th International Conference on Information and Communication Technology (ICoICT). 2019. IEEE.

[50] Sharma, S.K., et al., Structural equation model (SEM)-neural network (NN) model for predicting quality determinants of e-learning management systems. Behaviour \& Information Technology, 2017. 36(10): p. 1053-1066. https://doi.org/10.1080/0144929X.2017.1340973

[51] Mohammadi, H., Investigating users' perspectives on e-learning: An integration of TAM and IS success model. Computers in Human Behavior, 2015. 45: p. 359-374. https://doi. org/10.1016/j.chb.2014.07.044

[52] Huang, Y., Empirical analysis on factors impacting mobile learning acceptance in higher engineering education. 2014.

[53] Ni, L., Self-directed Learning: Teacher and computer technology assist. International Journal of Computer Networks and Wireless Communications (IJCNWC), 2013. 3(2): ISSN: 2250-3501. 2013. 3.

[54] Jawad, H.H.M., \& Z.B. Hassan, Applying UTAUT to evaluate the acceptance of mobile learning in higher education in Iraq. International Journal of Science and Research (IJSR), 2015. 4(5): p. 952-954.

[55] Sultana, J., Determining the factors that affect the uses of Mobile Cloud Learning (MCL) platform Blackboard-a modification of the UTAUT model. Education and Information Technologies, 2020. 25(1): p. 223-238. https://doi.org/10.1007/s10639-019-09969-1

[56] Huang, R.T., et al., Investigating the roles of perceived playfulness, resistance to change and self-management of learning in mobile English learning outcome. British Journal of Educational Technology, 2012. 43(6): p. 1004-1015. https://doi.org/10.1111/j.14678535.2011.01239.x

[57] Bere, A. Exploring determinants for mobile learning user acceptance and use: an application of UTAUT. in Information Technology: New Generations (ITNG), 2014 11th International Conference on. 2014. IEEE. https://doi.org/10.1109/ITNG.2014.114

[58] Abu-Al-Aish, A., \& S. Love, Factors influencing students' acceptance of m-learning: An investigation in higher education. The International Review of Research in Open and Distributed Learning, 2013. 14(5). https://doi.org/10.19173/irrodl.v14i5.1631

[59] Al-Hujran, O., E. Al-Lozi, \& M.M. Al-Debei, "Get Ready to Mobile Learning": Examining Factors Affecting College Students' Behavioral Intentions to Use M-Learning in Saudi Arabia. Jordan Journal of Business Administration, 2014. 10(1).

[60] Cheon, J., et al., An investigation of mobile learning readiness in higher education based on the theory of planned behavior. Computers \& Education, 2012. 59(3): p. 1054-1064. https:// doi.org/10.1016/j.compedu.2012.04.015 
[61] Nassuora, A.B., Students acceptance of mobile learning for higher education in Saudi Arabia. American Academic \& Scholarly Research Journal, 2012. 4(2): p. 1. https://doi. org/10.12785/ijlms/010101

[62] Suki, N.M., \& N.M. Suki, Users' behavior towards ubiquitous M-learning. Turkish Online Journal of Distance Education, 2011. 12(3).

[63] Wang, H.-Y., \& S.-H. Wang, User acceptance of mobile internet based on the unified theory of acceptance and use of technology: Investigating the determinants and gender differences. Social Behavior and Personality: An International Journal, 2010. 38(3): p. 415-426. https:// doi.org/10.2224/sbp.2010.38.3.415

[64] Alshehri, M., et al., The Effects of Website Quality on Adoption of E-Government Service: AnEmpirical Study Applying UTAUT Model Using SEM. arXiv preprint arXiv:1211.2410, 2012.

[65] Huang, R.-T., Exploring the Moderating Role of Self-Management of Learning in Mobile English Learning. Educational Technology \& Society, 2014. 17(4): p. 255-267.

[66] Donaldson, R.L., Student acceptance of mobile learning. 2010, THE FLORIDA STATE UNIVERSITY.

[67] Boontarig, W., et al. Factors influencing the Thai elderly intention to use smartphone for e-Health services. in 2012 IEEE Symposium on Humanities, Science and Engineering Research, 2012. IEEE. https://doi.org/10.1109/SHUSER.2012.6268881

[68] Feng, L., et al. An Investigation of Factors Influencing College Students' Mobile Learning Behavior in International Conference on Hybrid Learning and Continuing Education, 2015. Springer. https://doi.org/10.1007/978-3-319-20621-9 27

[69] Hair, J.F., W.C. Black, \& B.J. Babin, R.E. Anderson, Multivariate data analysis: A global perspective. New Jersey, Pearson Prentice Hall, 2010: p. 661-699.

[70] Almaiah, M.A., M.M. Alamri, \& W. Al-Rahmi, Applying the UTAUT model to explain the students' acceptance of Mobile learning system in higher education. IEEE Access, 2019. 7: p. 174673-174686. https://doi.org/10.1109/ACCESS.2019.2957206

[71] Demissie, D., \& D. Alemu, An Investigation into user Adoption of Personal Safety Devices in Higher Education Using the Unified Theory of Acceptance and Use of Technology (UTAUT). 2017.

[72] Barbara, B., Structural equation modeling with AMOS: basic concepts, applications, and programming. 2016, New York: Routledge.

[73] Byrne, B.M., Structural equation modeling with Mplus: Basic concepts, applications, and programming. 2013: Routledge. https://doi.org/10.4324/9780203807644

[74] Aliaño, Á.M., et al., Mobile learning in university contexts based on the unified theory of acceptance and use of technology (UTAUT). Journal of New Approaches in Educational Research (NAER Journal), 2019. 8(1): p. 7-17. https://doi.org/10.7821/ naer.2019.1.317

[75] Israel, D.J., \& R. Velu, The partial test of UTAUT model to explain the influence of variables on the intention to adopt the mobile learning in higher education. IJITEE, 2019. 8(8): p. 1076-1082.

[76] Almaiah, M.A., \& M. Man, Empirical investigation to explore factors that achieve high quality of mobile learning system based on students' perspectives. Engineering Science and Technology, an International Journal, 2016. 19(3): p. 1314-1320. https://doi.org/10.1016/j. jestch.2016.03.004

[77] Shah, S.R., M.A. Hussain, \& O.A. Nasseef, Factors impacting EFL teaching: An exploratory study in the Saudi Arabian context. Arab World English Journal, 2013. 4(3).

[78] Alkhunaizan, A., \& S. Love, What drives mobile commerce? An empirical evaluation of the revised UTAUT model. International Journal of Management and Marketing Academy, 2012. 2(1): p. 82-99. 
[79] Ng, K.S., et al., Factors influencing intention to use mobile technologies for learning among technical universities students. 2015.

[80] Moon, Y.-J., Y.-H. Hwang, \& S. Cho, An empirical study of impacts of user intention for smart wearable devices and use behavior, in Advanced Multimedia and Ubiquitous Engineering. 2016, Springer. p. 357-365. https://doi.org/10.1007/978-3-662-47895-0_43

[81] Alazzam, M.B., et al., Trust in stored data in EHRs acceptance of medical staff: using UTAUT2. International Journal of Applied Engineering Research, 2016. 11(4): p. 2737-2748.

[82] Arain, A.A., et al., Extending UTAUT2 toward acceptance of mobile learning in the context of higher education. Universal Access in the Information Society, 2019. 18(3): p. 659-673. https://doi.org/10.1007/s10209-019-00685-8

[83] Nikolopoulou, K., V. Gialamas, \& K. Lavidas, Acceptance of mobile phone by University students for their studies: An investigation applying UTAUT2 model. Education and Information Technologies, 2020. p. 1-17. https://doi.org/10.1007/s10639-020-10157-9

[84] Chin-ChehYi, P.-W.L., C.-F. Huang, \& I.-H. Hwang, Acceptance of mobile learning: a respecification and validation of information system success. International Journal of Human and Social Sciences, 2010. 5(7).

[85] Liu, Y., S. Han, \& H. Li, Understanding the factors driving m-learning adoption: a literature review. Campus-Wide Information Systems, 2010. https://doi.org/10.1108/ 10650741011073761

[86] Badwelan, A., S. Drew, \& A.A. Bahaddad, Towards acceptance m-learning approach in higher education in Saudi Arabia. International Journal of Business and Management, 2016. 11(8): p. 12. https://doi.org/10.5539/ijbm.v11n8p12

[87] Huang, R.-T. and C.-L. Yu, Exploring the impact of self-management of learning and personal learning initiative on mobile language learning: A moderated mediation model. Australasian Journal of Educational Technology, 2019. 35(3). https://doi.org/10.14742/ ajet. 4188

[88] Al-Adwan, A.S., A. Al-Adwan, \& H. Berger, Solving the mystery of mobile learning adoption in higher education. International Journal of Mobile Communications, 2018. 16(1): p. 24-49. https://doi.org/10.1504/IJMC.2018.10007779

[89] Teo, T., \& M. Zhou, The influence of teachers' conceptions of teaching and learning on their technology acceptance. Interactive Learning Environments, 2017. 25(4): p. 513-527. https://doi.org/10.1080/10494820.2016.1143844

[90] Odewumi, M.O., M.O. Yusuf, \& G.O. Oputa, UTAUT Model: Intention to Use Social Media for Learning Interactive Effect of Postgraduate Gender in South-West Nigeria. International Journal of Education and Development using Information and Communication Technology, 2018. 14(3): p. 239-251.

[91] eMarketer. Smartphones, tablets spread across the Middle East and Africa. 2015; Available from: http://www.emarketer.com/Article/Smartphones-Tablets-Spread-AcrossMiddleEast-Africa/1012989

[92] National Transformation Program. National Transformation Program 2020. 2016; Available from: http://vision2030.gov.sa/sites/default/files/NTP_En.pdf

[93] Nguyen, D., Understanding perceived enjoyment and continuance intention in mobile games. 2015. 


\section{Authors}

Fahad Alturise is currently working as an Associate Professor in the Computer Department, College of Science and Arts in Ar Rass, Qassim University, Saudi Arabia. He has a total of twelve years of research and teaching experience. Flinders University awarded him a PhD in Information Technology. E-learning, e-services, e-government, IoT, ICT adaptation, IT security, and software engineering are among his major research interests. He has twelve publications in international conferences and journals to his credit. For four years, he was a member of the Australian Computer Society (ACS). Email: falturise@qu.edu.sa.

Sami Alshmrany has been an Assistant Professor of Information Technology since October 2018. He finished his BSc in Computer Science from the University of King Abdulaziz, Jeddah, Saudi Arabia in 2008. In 2009, he moved to Adelaide, Australia for further studies. He joined Flinders University, Adelaide, Australia and obtained his MSc in Information Technology in 2013. In 2018, he finished his PhD in information technology from Flinders University, Adelaide, Australia. Email: s.alshmrany@iu.edu.sa.

Tamim Alkhalifah is currently working as an Assistant Professor in the Computer Department, College of Science and Arts in Ar Rass, Qassim University, Saudi Arabia. He was accepted into a full-time CS master's program at Swansea University in 2009. He began his studies at Flinders University in Adelaide, Australia, in 2013, and graduated with a $\mathrm{PhD}$ in computer science in 2018. E-technologies, mobile learning, mobile development, and gamification are among his major research interests. In the subject of information technology, he authored numerous publications. Email: tkhliefh@qu.edu.sa.

Salem Alkhalaf is an Associate Professor in the Computer Department at Qassim University, Saudi Arabia. In 2013, he received his PhD in Information and Communication Technology from Griffith University. He was also a member of the Saudi National Team for Measuring E-Government in Saudi Arabia for two years. Finally, eSystems (eGov, eHealth, ecommerce, etc.) and information and communications technology are among his current research interests (ICT).

Article submitted 2021-07-22. Resubmitted 2021-10-08. Final acceptance 2021-10-13. Final version published as submitted by the authors. 